\title{
Identification of Anaplasma ovis appendage-associated protein (AAAP) for development of an indirect ELISA and its application
}

Zhenguo Wang ${ }^{1}$, Jifei Yang ${ }^{1}$, Qingli Niu', Kelly A. Brayton², Jianxun Luo ${ }^{1}$, Guangyuan Liu', Hong Yin ${ }^{1}, 3$ and Zhijie Liu ${ }^{1 *}$

\begin{abstract}
Background: Ovine anaplasmosis is a tick-borne disease that is caused by Anaplasma ovis in sheep and goats. The pathogen is widely distributed in tropical and subtropical regions of the world. At present, diagnosis of the disease mainly depends on microscopy or nucleic acid based molecular tests, although a few serological tests have been applied for the detection of $A$. ovis infection.

Results: Here we describe the identification of an A. ovis protein that is homologous to the A. marginale appendageassociated protein (AAAP). We expressed a recombinant fragment of this protein for the development of an indirect enzyme-linked immunosorbent assay (ELISA) for the detection of A. ovis. Anaplasma ovis-positive serum showed specific reactivity to recombinantly expressed AAAP (rAAAP), which was further confirmed by the rAAAP ELISA, which also demonstrated no cross-reactivity with sera from animals infected with A. bovis or other related pathogens in sheep and goats. Testing antibody kinetics of five experimentally infected sheep for 1 year demonstrated that the rAAAP ELISA is suitable for the detection of early and persistent infection of A. ovis infections. Investigation of 3138 fieldcollected serum samples from 54 regions in 23 provinces in China demonstrated that the seroprevalence varied from $9.4 \%$ to $65.3 \%$, which is in agreement with previous reports of $A$. ovis infection.

Conclusions: An A. ovis derived antigenic protein, AAAP, was identified and the antigenicity of the recombinant AAAP was confirmed. Using rAAAP an indirect ELISA assay was established, and the assay has been proven to be an alternative serological diagnostic tool for investigating the prevalence of ovine anaplasmosis of sheep and goats.
\end{abstract}

Keywords: Anaplasma ovis, AAAP, ELISA, Seroprevalence

\section{Background}

Ovine anaplasmosis is a tick-borne disease of sheep, goats and small ruminants caused by Anaplasma ovis [1-3]. Anaplasma ovis is a non-motile, obligate intraerythrocytic Gram-negative bacterium that belongs to the order Rickettsiales [4]. Following the reorganisation of the order in 2001, this pathogen is classified along with $A$. marginale, A. centrale, A. bovis and A. caudatum which infect ruminants, $A$.

\footnotetext{
* Correspondence: liuzhijie@caas.cn

'State Key Laboratory of Veterinary Etiological Biology, Key Laboratory of Veterinary Parasitology of Gansu Province, Lanzhou Veterinary Research Institute, Chinese Academy of Agricultural Sciences, Lanzhou, People's Republic of China

Full list of author information is available at the end of the article
}

phagocytophilum a zoonotic agent, and $A$. platys that infects dogs [4]. Biological vectors of $A$. ovis are ticks of the genera Dermacentor and Rhipicephalus and most likely other tick species [5-9]. The study of $A$. ovis was often neglected since it is considered to be moderately pathogenic and induce only mild clinical signs $[7,10]$. However, A. ovis infection resulting in severe disease has been reported in bighorn sheep, goats and sheep $[9,11,12]$. Although the pathogen is known to be widespread in tropical and subtropical countries, the extent of infection and the loss of livestock productivity remain poorly understood $[7,12]$.

The detection of $A$. ovis in livestock has traditionally been based on the identification of acute infections, using a 
microscopic examination of Giemsa-stained blood smears. Light microscopy is the most inexpensive and quickest laboratory test, but also the least sensitive, and is highly dependent on examiner experience $[12,13]$. Moreover, it is crucial that the smears should be prepared during the early acute phase of signs and before initiation of effective antimicrobial treatments. Nucleic acids based tests, such as polymerase chain reaction (PCR), quantitative real-time PCR (qPCR), and loop-mediated isothermal amplification (LAMP) have been alternative tests for the direct detection of $A$. ovis infection in both experimental and field studies [14-16]. These methods are restricted by the limited sensitivity of the detection in persistently infected carrier animals with very low-level bacteremia [13, 17]. In contrast, serological tests have the advantage of detecting antibodies from infected animals during all stages of Anaplasma infection [18].

A recombinant $A$. marginale major surface protein 5 (Msp5) based competitive inhibition enzyme-linked immunosorbent assay (CI-ELISA) has been developed and shown to detect $A$. marginale-infected cattle, including persistently infected carriers [19]. This assay was later confirmed to be suitable for the detection of antibodies to $A$. ovis infected goats due to the conservation of Msp5 epitopes among Anaplasma strains [12, 20], and it was also found to detect antibodies from $A$. phagocytophilum and Ehrlichia species [21, 22]. Because of the potential for cross-reaction when using the CI-ELISA, the results need to be interpreted cautiously. In this paper, we describe the identification of an A. ovis antigenic protein, AAAP, and the development of an indirect ELISA for the specific detection of $A$. ovis in sheep and goats.

\section{Methods}

\section{Bacteria and experimental animals}

The $A$. ovis isolate used in this study was obtained from an infected sheep in Haibei County in Qinghai Province, and the blood containing live pathogens and 8\% dimethyl sulfoxide (DMSO) has been cryopreserved in liquid nitrogen since 2008 at the Lanzhou Veterinary Research Institute, Chinese Academy of Agricultural Sciences.

Three-month-old sheep were purchased from a commercial farm in Jingtai County, Gansu Province. The sheep were screened for the absence of A. ovis, Babesia and Theileria by weekly examination of blood smear by light microscopy and previously described PCR protocols specific for each pathogen for a month before conducting animal experiments [3, 23, 24].

Sheep No. 101 was splenectomized to ensure rapid initiation and propagation of the infection by intravenously inoculating $10 \mathrm{ml}$ of infected A. ovis cryopreserved blood (approximately $10 \%$ bacteremia). Eight sheep (Nos. 420, 470, 489, 103, 106, 134, 174 and 183) were used to collect serum.

\section{Preparation of serum samples}

Sheep (Nos. 103, 106, 134, 174, 183) were infected by inoculating each animal with $5 \mathrm{ml}$ of bacteremic blood that had been collected from sheep No. 101 when the bacteremia was approximately $10 \%$. The serum samples were collected every 2 days for the first 15 days, followed by twice a week till 43 days, once a week till 85 days, once 2 weeks till 181 days and once a month till a year period. Sheep (Nos. 420, 470, 489) were infected by inoculation of infected blood from sheep No. 101 twice in two-week intervals for hyperimmune serum preparation. The serum samples were prepared immediately after $A$. ovis was observed in the thin blood smears. Positive sheep sera against A. bovis, Mycoplasma ovipneumoniae, Mycoplasma capricolum capricolum, Babesia motasi, Babesia sp. Xinjiang, Theileria uilenbergi and Theileria luwenshuni, and positive yak sera against $A$. marginale were obtained from previous collections and stored at $-20^{\circ} \mathrm{C}$ in our laboratory.

Serum samples from sheep (Nos. 103, 106, 134, 174, $183,420,470,489$ ) before infection were used as negative controls. An additional 434 negative samples were obtained from experimental animals purchased from 2009 to 2016. These animals were determined to be free of $A$. ovis, Babesia and Theileria spp. as described above.

Field samples $(n=3138)$ were randomly collected from domestic sheep and goats from 54 different locations in 23 provinces between 2010 and 2016 (Fig. 1). All samples were collected in non-anticoagulation tubes, and the serum was separated and stored at $-20{ }^{\circ} \mathrm{C}$ in our laboratory.

\section{DNA specimens}

Whole blood was taken from the jugular vein of each experimentally infected animal and collected in a sterile tube containing an anticoagulant (ethylene diamine tetraacetie acid, EDTA). DNA was extracted from the blood using a genomic DNA extraction kit (Qiagen, Hilden, Germany) according to the manufacturer's instructions.

\section{Bacterial purification}

The venous blood from sheep No. 101 (10\% bacteremia) was harvested in a sterile flask containing anticoagulant (EDTA). The red blood cells were separated by centrifugation at $1000 \times g$ for $10 \mathrm{~min}$, and the upper layer containing the white blood cells was discarded. The packed red blood cells were suspended in phosphate-buffered saline (PBS, $\mathrm{pH}$ 7.2), and then the remaining white blood cells were removed using a commercial leucocyte filter (Nanjing Shuangwei Biotechnology, Nanjing, China). The flowthrough was centrifuged as above, and the supernatant was discarded. The harvested red blood cells were suspended in four volumes of PBS containing 7\% glycerin and placed at room temperature for $30 \mathrm{~min}$, and then centrifuged again to harvest the red blood cells. The cells were then added to a flask containing four volumes of physiological saline to let 


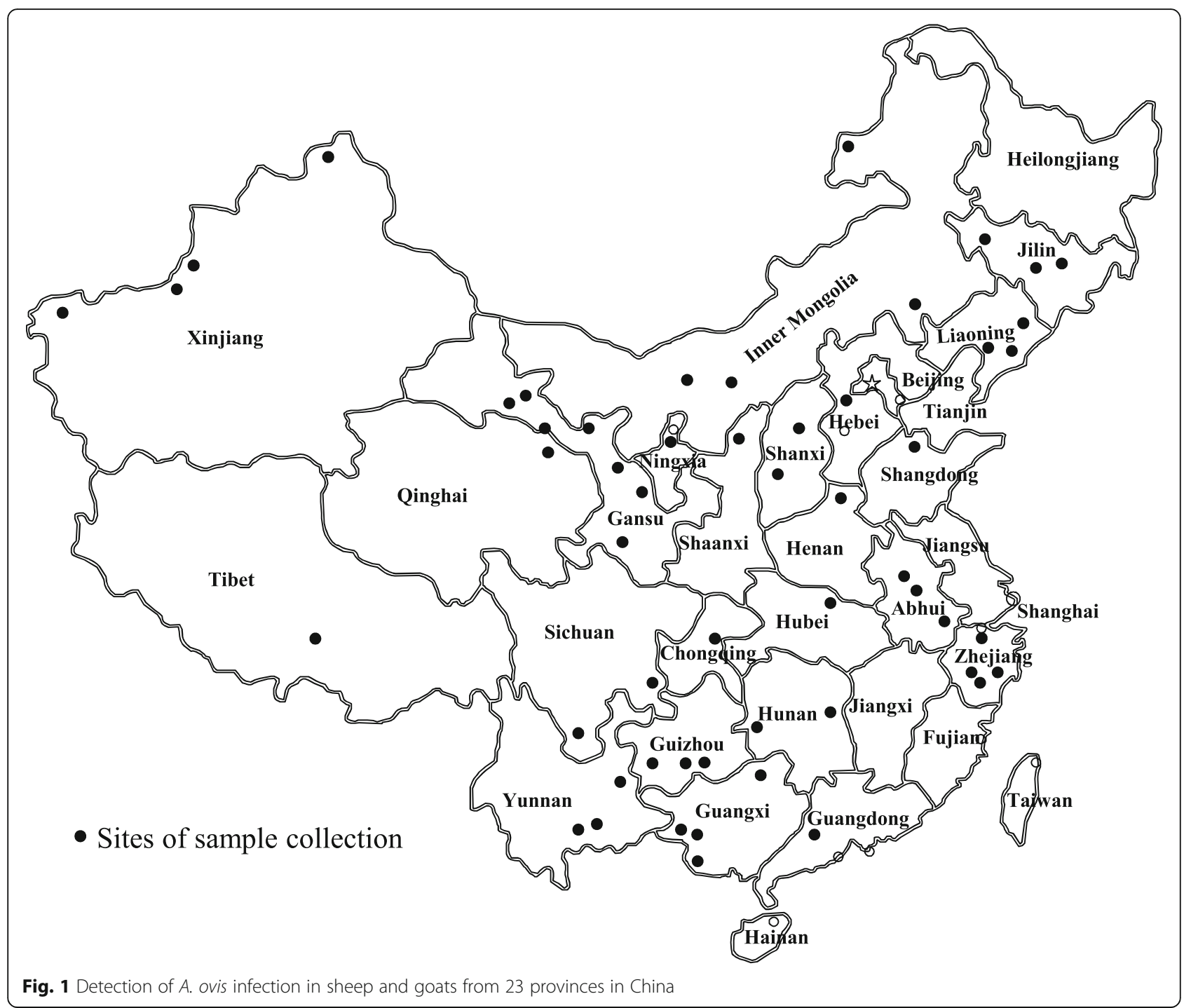

the cells lyse completely. The lysate was centrifuged at $1000 \times g$ for $10 \mathrm{~min}$ to get rid of cell debris. The supernatant was then centrifuged at $10,000 \times g$ for $30 \mathrm{~min}$ to collect the bacterial pellet. The pellet was washed three times with physiological saline by centrifugation at $10,000 \times g$ for $10 \mathrm{~min}$. The white pellet at the bottom of the tube was the purified bacteria, which were then stored at $-70{ }^{\circ} \mathrm{C}$ till use.

\section{Immunoprecipitation and mass spectrometric analysis}

Fifteen $\mu$ g sepharose beads (CNBr-activated Sepharose ${ }^{\mathrm{TM}}$ 4B, GE Healthcare Life Sciences, Beijing, China) were added to $500 \mu \mathrm{l} 0.1 \mathrm{mM} \mathrm{HCl}$ and gently mixed for $15 \mathrm{~min}$. Agarose was pelleted by centrifugation at $12,000 \times g$ at room temperature for $10 \mathrm{~s}$, and then resuspended in $600 \mu \mathrm{l}$ washing buffer $(0.1 \mathrm{mM} \mathrm{HCL})$ and divided into 6 aliquots of $100 \mu \mathrm{l}$ in $1.5 \mathrm{ml}$ tubes. Equal amounts of sheep (Nos. 420, 470, 489) sera before and after infection was added into each tube respectively and incubated at room temperature for $30 \mathrm{~min}$ with gentle shaking. The agarose and antibody conjugates were pelleted by centrifugation at $3000 \times g$ at $4{ }^{\circ} \mathrm{C}$ for $2 \mathrm{~min}$, and the conjugates were washed three times using washing buffer. The purified bacteria were lysed using RIPA lysis buffer (Beyotime, Beijing, China), and $200 \mu \mathrm{l}$ of bacterial lysates containing approximately $500 \mu \mathrm{g}$ of antigen were added to the conjugates and incubated at $4{ }^{\circ} \mathrm{C}$ overnight with gentle shaking. The samples were centrifuged to collect immunoprecipitation complexes at $3000 \times g$ at $4{ }^{\circ} \mathrm{C}$ for $2 \mathrm{~min}$. The complexes were washed three times using washing buffer. The antibody-antigen conjugates were eluted by washing with $20 \mu \mathrm{l}$ elution buffer $(100 \mathrm{mM}$ Glycine, $\mathrm{pH}$ 2.5). The resulting samples were used for sodium dodecyl sulfate-polyacrylamide gel electrophoresis (SDS-PAGE) analysis. The separated bands were digested with trypsin at $37{ }^{\circ} \mathrm{C}$ overnight. Peptides were extracted with $50 \%$ acetonitrile (ACN, Fisher Chemical, Shanghai, 
China) containing 5\% formic acid (FA, Fluka, Shanghai, China), followed by $100 \% \mathrm{ACN}$. The peptides were dried and then resuspended in $2 \% \mathrm{ACN}$ containing $0.1 \% \mathrm{FA}$. The peptides were then identified using liquid chromatographyelectrospray ionisation tandem mass spectrometry (LCESI-MSMS) (Triple TOF 5600, AB SCIEX, Concord). Resulting values for monoisotopic peaks were analysed using the computer program Mascot [25]. The sequences obtained from the mass spectrometry were used to identify the full-length open reading frame by search and alignment against an ongoing genome sequencing project for $A$. ovis strain Haibei (GenBank accession no. CP015994).

\section{Cloning of the truncated aaap gene}

PCR primers were designed based on the aaap gene sequence from the $A$. ovis strain Haibei genome sequence. The restriction sites, EcoR I and Hind III were introduced into the $5^{\prime}$ and $3^{\prime}$ primers, respectively. The primers were aaap-F: 5' -CCG GAA TTC AGG GTA CTG GTA ATG GGC-3' and aaap-R: 5'-CCC AAG CTT CTA AAT AGC AAG ACT TTG CGT ATT AG-3'. Genomic DNA from an infected blood sample from sheep No. 101 served as a template for the PCR.

The PCR had a total volume of $25 \mu \mathrm{l}$ containing $12.5 \mu \mathrm{l}$ Premix Taq ${ }^{\text {Tix }}$ (TaKaRa Taq ${ }^{\text {Tw }}$ Version 2.0 plus dye), $0.5 \mu \mathrm{l}$ of each primer $(20 \mu \mathrm{M}), 2.0 \mu \mathrm{l}$ of template DNA, and $9.5 \mu \mathrm{l}$ of distilled water. The cycling conditions were as follows: 4 min of denaturation at $94{ }^{\circ} \mathrm{C}, 35$ cycles at $94{ }^{\circ} \mathrm{C}$ for $1 \mathrm{~min}$, annealing at $55{ }^{\circ} \mathrm{C}$ for $30 \mathrm{~s}$, and $72{ }^{\circ} \mathrm{C}$ for $1 \mathrm{~min}$, with a final extension step at $72{ }^{\circ} \mathrm{C}$ for $10 \mathrm{~min}$. The PCR products were cloned into the pGEM-T-Easy Vector (Promega, Beijing, China), according to the manufacturer's instructions, and then digested using EcoR I and Hind III restriction enzymes (New England Biolabs, Hitchin, UK). The resulting fragment was subsequently cloned into the pET-30a expression vector (Novagen, Shanghai, China) using the same restriction sites. The correct insertion of the aaap gene fragment was confirmed by sequencing (Sangon Biotech Company, Shanghai, China).

\section{Expression and purification of the recombinant AAAP protein}

The recombinant plasmid pET-30a-P35 was transformed into BL21 E. coli (DE3 strain). The cells were cultured in $\mathrm{LB}$ medium at $37^{\circ} \mathrm{C}$ for $6 \mathrm{~h}$ and expression was induced by addition of $1 \mathrm{mM}$ isopropyl- $\beta$-d-thiogalactoside (IPTG) when the optical density (OD) reached 0.6 . The bacterial cultures were harvested and lysed by ultrasonication in binding buffer $(20 \mathrm{mM}$ imidazole, $20 \mathrm{mM}$ sodium phosphate, $0.5 \mathrm{M} \mathrm{NaCl}, 8 \mathrm{M}$ Urea, $\mathrm{pH}$ 7.6) and then purified as inclusion bodies from E. coli cells. The target protein was purified with the AKTA design system (Amersham Bioscience, Uppsala, Sweden) using $5 \mathrm{ml}$ HiTrap FF crude. The column was washed with 3-5 column volumes of distilled water and then equilibrated with at least 5 column volumes of binding buffer. The flow rate was $2 \mathrm{ml} /$ $\mathrm{min}$ for $5 \mathrm{ml}$ columns. The pretreated sample was applied using a syringe pump, and then the column was washed with binding buffer $(80 \mathrm{mM}$ imidazole, $20 \mathrm{mM}$ sodium phosphate, $0.5 \mathrm{M} \mathrm{NaCl}, 8 \mathrm{M}$ Urea, $\mathrm{pH}$ 7.6) until the absorbance reached a steady baseline. The sample was eluted with elution buffer $(250 \mathrm{mM}$ imidazole, $20 \mathrm{mM}$ sodium phosphate, $0.5 \mathrm{M} \mathrm{NaCl}, 8 \mathrm{M}$ Urea, $\mathrm{pH}$ 7.6) until the absorbance reached a steady baseline.

\section{Preparation of AAAP specific rabbit immune serum}

Two New Zealand white rabbits were immunised three times by injecting with $200 \mu \mathrm{g}$ of recombinant AAAP protein at 2-week intervals. For the first immunisation, the recombinant AAAP protein was emulsified with Freund's complete adjuvant (FCA) (Sigma-Aldrich, Shanghai, China) at a ratio of 1:1. For the remaining immunisations, AAAP was emulsified with incomplete Freund's adjuvant at a ratio of 1:1. Serum samples were collected 2 weeks after the last immunisation, and stored at $-20{ }^{\circ} \mathrm{C}$ until use.

\section{Western blotting analysis}

Optimal amounts of the recombinant protein AAAP and the crude antigen (Bacterial lysate) were separated in SDSPAGE using $12 \%$ polyacrylamide gels under reducing conditions and transferred to nitrocellulose (NC) membranes. The NC membranes were blocked with $5 \%$ skimmed milk powder in $0.1 \mathrm{M}$ Tris-buffered saline (pH 7.6) containing $0.1 \%$ Tween-20 (TBST) at $4{ }^{\circ} \mathrm{C}$ overnight. To verify the expression and purification of the recombinant protein AAAP, the RGS-His ${ }^{\mathrm{ma}}$ mouse anti-histidine antibody (1:4000, Qiagen, Hilden, Germany) and secondary alkaline phosphatase (AP) conjugated goat anti-mouse IgG + IgM $(\mathrm{H}+\mathrm{L})$ antibody (1:10,000, Dianova, Hamburg, Germany) were used to detect the His-tag on the recombinant protein. To test the antigenicity and specificity of recombinant proteins, 1:100 diluted sheep serum samples positive for $A$. ovis, A. bovis, M. ovipneumoniae, M. capricolum capricolum, B. motasi, Babesia sp. Xinjiang, T. uilenbergi, T. luwenshuni, as well as negative control serum from uninfected sheep were used as primary antibody and 1:5000 diluted AP conjugated monoclonal anti-goat/sheep secondary antibody (Sigma-Aldrich) were used. To detect native AAAP, pre-immunization rabbit serum and rabbit AAAP antiserum were tested with the crude antigen on western blot. The secondary antibody was AP-conjugated goat antirabbit immunoglobulin antibody (1:5000, Sigma-Aldrich). All of the serum samples and the secondary antibodies were diluted in dilution buffer (TBST containing 1\% bovine serum albumin, $\mathrm{pH}$ 7.2). Binding of secondary antibody was detected with 5-bromo-4-chloro-3-indolyl phosphate (BCIP)/ nitroblue tetrazolium (NBT) substrate (SigmaAldrich). The approximate molecular weights of the 


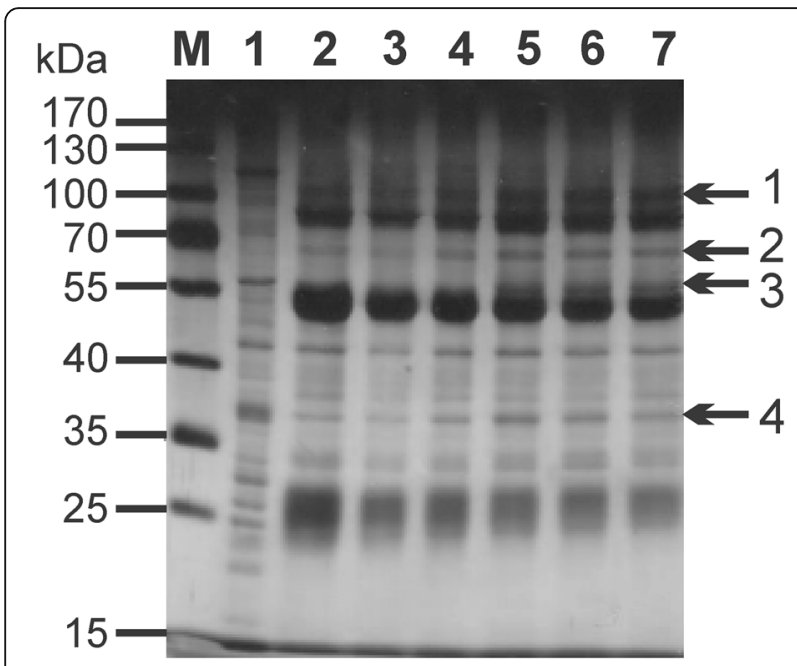

Fig. 2 Silver staining of SDS-PAGE gel for analysis of A. ovis lysates immune- precipitation. Lane 1: A. ovis lysates; Lanes 2-4: A. ovis lysates immunoprecipitation with sera from pre-immunized sheep (Nos. 420, 470, 489); Lanes 5-7: A. ovis lysates immunoprecipitation with sera from A. ovis infected sheep (Nos. 420,470, 489). Numbers at right side indicate four differently expressed bands, and band 4 was predicted to be AAAP

presented protein bands were calculated by comparing their migrations with the standard Protein Ladder (Thermo Scientific, Beijing, China).

\section{ELISA}

A checkerboard titration was used to determine the concentration of coating antigen $(1.5,2.0,2.5,3.0 \mu \mathrm{g} / \mathrm{ml})$, serum (1:50, 1:100, 1:200, 1:400 dilutions) and conjugate (1:15,000, 1:20,000, 1:25,000 dilutions). The optimum conditions were set as follow. Briefly, the plates (JET BIOFIL, Canada) were coated with $2.5 \mu \mathrm{g} / \mathrm{ml}$ of recombinant protein AAAP in 0.1 M carbonate/bicarbonate buffer, $\mathrm{pH}$ 9.6, at $4{ }^{\circ} \mathrm{C}$ overnight. After 3 washes with PBS containing
$0.1 \%$ Tween 20 (PBST), the plates were blocked with $100 \mu \mathrm{l}$ of $1 \%$ gelatin in carbonate/bicarbonate buffer at $37^{\circ} \mathrm{C}$ for $1 \mathrm{~h}$. After 3 washes with PBST, the plates were incubated at $37^{\circ} \mathrm{C}$ for $1 \mathrm{~h}$ with $100 \mu \mathrm{l}$ of the positive and negative sera (1:100) which were distributed in duplicate. The positive sera were a mixture from hyperimmune sheep 420, 470, 4892 weeks after second infected-blood inoculation as described above and the negative serum was from sheep 420 before infected-blood inoculation. The plates were washed with the same procedure and incubated with $100 \mu \mathrm{l}$ of secondary antibody (anti-goat/ sheep IgG-peroxidase, Sigma-Aldrich, 1:20,000) in PBST at $37{ }^{\circ} \mathrm{C}$ for $1 \mathrm{~h}$. The plates were washed 3 times, and $100 \mu \mathrm{l}$ of 3,3',5,5'--tetramethylbenzidine (TMB, KPL, 5200-03) was added to each well and incubated at $37^{\circ} \mathrm{C}$ for $10 \mathrm{~min}$. The reaction was stopped by adding $100 \mu \mathrm{l}$ of $2 \mathrm{M} \mathrm{H}_{2} \mathrm{SO}_{4}$ and the OD (450 $\left.\mathrm{nm}\right)$ values were read using an ELISA automat (Bio-Rad, California, USA). The specific antibody mean rate (AbR\%) was calculated for each serum sample with the following formula, $\mathrm{AbR} \%=($ Sample mean OD - Negative control mean OD)/(Positive control mean OD - Negative control mean OD) $\times 100 \%$.

\section{Results}

\section{Identification of $A$. ovis aaap}

We performed immunoprecipitation assays using $A$. ovis bacterial protein extracts and serum samples collected from $A$. ovis infected animals. As a control, serum from animals before infection was used with the same bacterial extracts. In the immunoprecipitation assay, four bands were detected as a novel or at higher densities in the group immunoprecipitated with the positive sera as compared with the control group immunoprecipitated with the negative sera as shown in Fig. 2. These bands were further analysed using mass spectrometry, and the resulting peptide sequences were BLASTed against the $A$. ovis genome. Band 4 was identified as aaap, which corresponds to

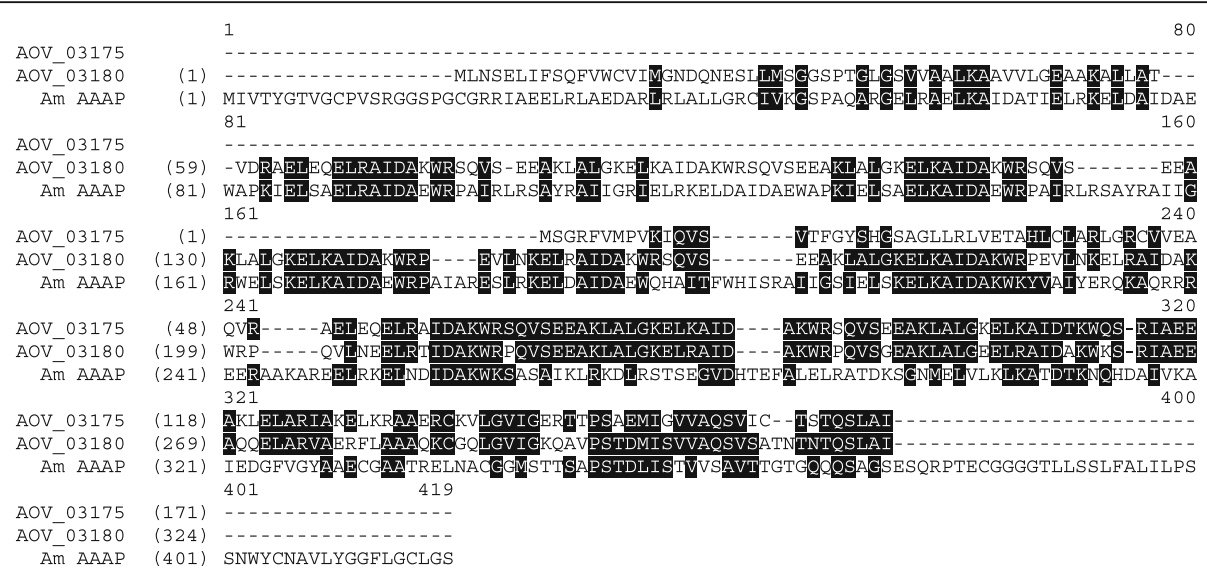

Fig. 3 Alignment of AAAP sequences. The deduced amino acid sequences of the full length AAAP gene (AOV_3180) and the partial gene (AOV_3175) from A. ovis are shown aligned with the original AAAP protein sequence from A. marginale (Am AAAP) 


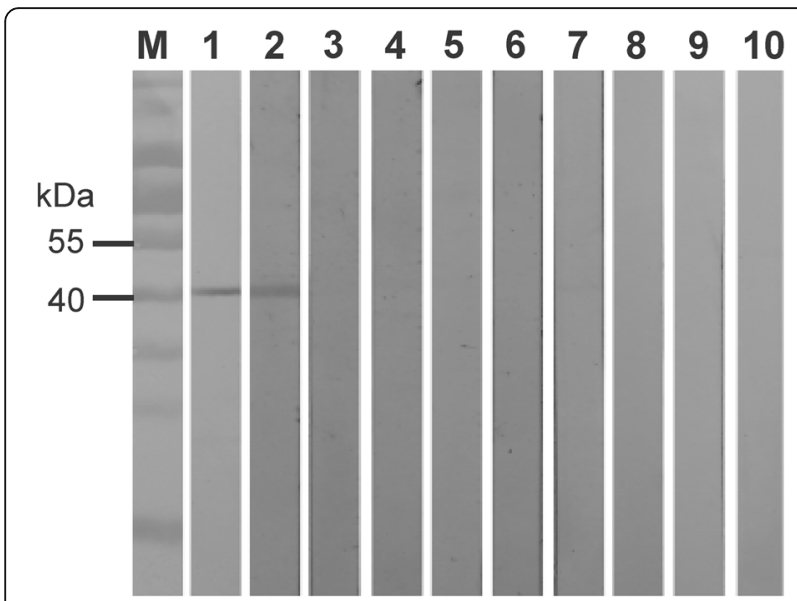

Fig. 4 Specificity and assessment of cross-reactivity of recombinant AAAP using Western blot. Lane M: molecular weight marker; Lanes 1-11 had $5 \mu \mathrm{g}$ of purified rAAAP blotted, which was then reacted with the primary antibodies as follows: Lane 1: mouse anti-RGS-His antibody; Lane 2: A. ovis-positive sheep serum; Lane 3: serum from uninfected sheep; Lane 4-9, 11: positive sheep sera against Mycoplasma ovipneumoniae, M. capricolum capricolum, Babesia motasi, Babesia sp. Xinjiang, Theileria uilenbergi, T. luwenshuni and A. bovis, respectively; Lane 10: positive cattle serum against $A$. marginale

AOV_03180 with an open reading frame of $972 \mathrm{bp}$ in size. The translated protein contains 323 amino acids with a predicted molecular weight of $35.5 \mathrm{kDa}$. The aaap sequence has been deposited in GenBank with accession number KY670611. There is a second gene in the genome in tandem with AOV_03180 that has similar features, designated AOV_03175, which appears to be a truncated version of aaap (Fig. 3). The deduced amino acid sequence of aaap showed $31 \%$ identity to the appendage-associated protein of A. marginale (AAAP; AM878; GenBank accession no. AAV86790) (Fig. 3).

A truncated aaap fragment encoding 299 amino acids (aa 25-323) was cloned into the pET-30a expression vector for recombinant protein expression. The pET-30a-P35 plasmid was expected to express an rAAAP protein with a molecular weight of $40.0 \mathrm{kDa}$. When the rAAAP was tested for reactivity with $A$. ovis-positive serum samples, a clear band of the appropriate size was observed, while no cross-reactivity was seen with serum samples containing antibodies to $M$. ovipneumoniae, $M$. capricolum capricolum, B. motasi, Babesia sp. Xinjiang, T. uilenbergi, T. luwenshuni, $A$. bovis or negative serum samples from healthy sheep (Fig. 4). This result indicated that the aaap gene encodes a potential antigenic protein of $A$. ovis.

To identify native AAAP protein in A. ovis, rabbit antirAAAP protein serum was prepared and used in Western blot analysis with purified $A$. ovis lysates. Both native AAAP protein in the lysates and the rAAAP protein were recognised by the rabbit anti-rAAAP sera, while no reaction was observed when preimmune rabbit sera were used (Fig. 5). The molecular weight of native AAAP appeared lower than rAAAP in the Western blot, most likely due to an extended protein structure of rAAAP leading to a retarded migration during electrophoresis $(34,35)$. These data confirmed the $A$. ovis origin and antigenicity of the AAAP protein.

\section{Establishment of the rAAAP indirect ELISA}

The rAAAP based indirect ELISA was eventually established with $100 \mu \mathrm{l}$ of $2.5 \mu \mathrm{g} / \mathrm{ml}$ rAAAP protein, $100 \mu \mathrm{l}$ of a 1:100 dilution of each serum sample to be tested, and $100 \mu \mathrm{l}$ of 1:20,000 diluted secondary antibody in each well in the reaction system. These conditions were used in all subsequent experiments.

The cut-off value of the ELISA was determined using interactive dot diagram (MedCalc software, version 11.4.2.0) [26] by testing 597 reference sera (434 negative sera and 163 positive sera). It was defined using the percentage of the specific antibody mean rate (AbR\%), which was eventually set to be $6.0 \%$. With this threshold, 25 false positive and 14 false negative sera were detected, resulting in a calculated sensitivity and specificity of 91.4\% (95\% confidence interval, CI: 86.0-95.2) and 94.5\% (95\% CI: 91.9-96.4), respectively (Fig. 6).

The specificity of the rAAAP indirect ELISA was evaluated using control samples, which were used previously in Western blot analysis and yak serum samples of $A$. marginale. The positive results were detected with

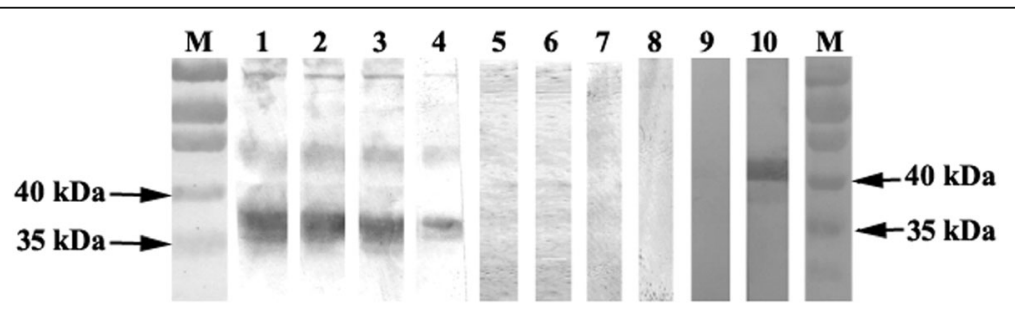

Fig. 5 Identification of native AAAP form the different weight lysate of A. ovis in Western blot. Lane M: molecular weight marker; Lanes 1-8: blotted with A. ovis lysate (Lanes 1 and 5: $20 \mu \mathrm{g}$; Lanes 2 and 6, $15 \mu \mathrm{g}$; Lanes 3 and 7, $10 \mu \mathrm{g}$; Lanes 4 and 8, $5 \mu \mathrm{g}$ ); Lanes 9-10: blotted with recombinant AAAP, reacted with rabbit anti-rP35 antibody; Lanes 1-4, 10, reacted with rabbit anti-rAAAP antibody; Lanes $5-$ 9, reacted with pre-immunized rabbit serum 


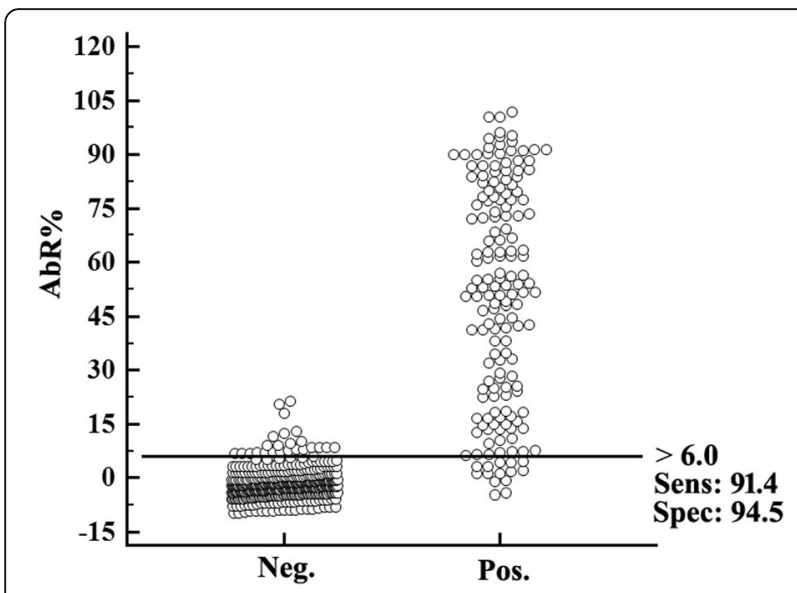

Fig. 6 Determination of ELISA cut-off value. The cut-off value of the rAAAP ELISA was determined to be $6.0 \%$ by testing 434 negative and 163 positive reference sera using interactive dot diagram. With this threshold, the calculated sensitivity and specificity were 95.1 and $95.4 \%$, respectively

the $A$. ovis-positive, and A. marginale-positive serum (Fig. 7), and no cross-reactivity was seen with the serum samples from A. bovis, M. ovipneumoniae, $M$. capricolum capricolum, Babesia sp. Xinjiang, B. motasi, T. uilenbergi, or T. luwenshuni (Fig. 8).

\section{The kinetics of antibody response in experimentally infected sheep}

The serum samples from five experimentally infected sheep (Nos. 103, 106, 134, 174, and 183) were collected at different time points during infection. These samples were used to test the kinetics of antibody response against rAAAP using the established ELISA (Fig. 9). A significant increase of antibodies against rAAAP was observed after the sheep were infected. However, the earliest antibody response differed from 5 to 13 days post-infection between individual animals. From then on, a sharp increase of antibody response was observed, and the infected animals

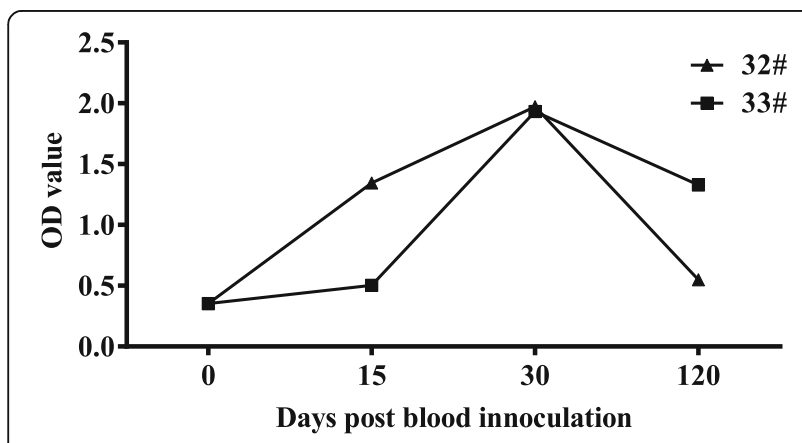

Fig. 7 Evaluation of the cross-reactivity of the rAAAP ELISA. Cross-reactivity with A. marginale-positive sera collected from yaks (Nos. 32, 33) by time course after infected blood inoculation

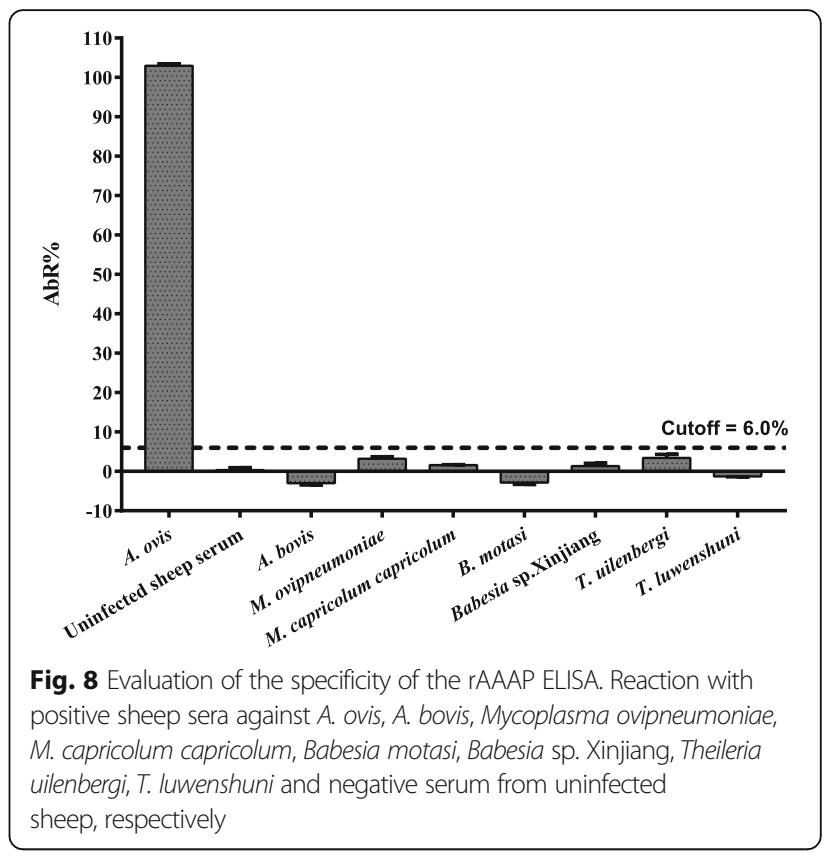

typically retained high antibody titers for approximately 100 days, when antibody a cycling pattern of decreasing and increasing antibody titers appeared in some of the animals (especially Nos. 103, 174). Moreover, the antibody response could be detected a year after infection, indicating that a test is a suitable tool for monitoring persistent $A$. ovis infections.

\section{Detection of the field samples with the rAAAP indirect ELISA}

The rAAAP indirect ELISA tested the field samples. The results showed that the mean positive rate was $35.3 \%$ (1106/3138) with the highest positive rate of $66.7 \%$ (66/ 99) in Yunnan Province and the lowest rate of 9.4\% (8/ 85) in Henan Province (Table 1).

\section{Discussion}

Ovine anaplasmosis has been neglected perhaps due to knowledge gaps on its pathogenicity, morbidity, mortality, clinical signs and economic losses. The causative agent, $A$. ovis, is considered as a moderate pathogen typically inducing only subclinical signs $[4,7]$. However, an exception was found in sheep and goats in Ejinaqi, Western Inner Mongolia in China, where the morbidity of the disease was as high as $40-50 \%$ and the mortality was $17 \%$, and the clinical signs such as anemia, jaundice and emaciation were observed [9]. Anaplasma ovis infection causing severe disease has also been reported in bighorn sheep, domestic sheep and goats in North America and Africa [11, 12]. The A. ovis Haibei strain used in this study caused several deaths in sheep herds in Haibei County in Qinghai Province in 2008. In addition, when healthy and splenectomized 

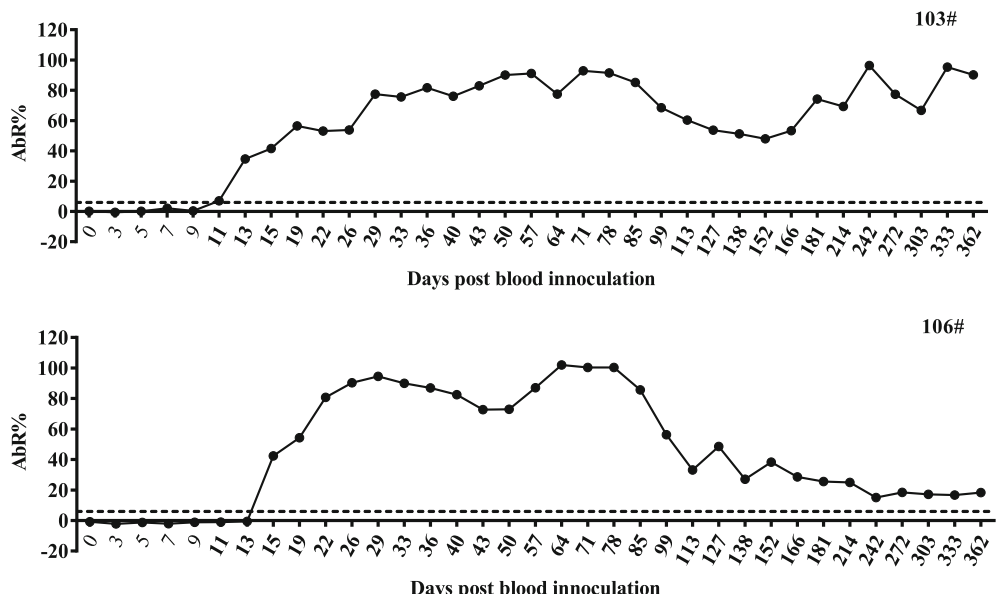

Days post blood innoculation
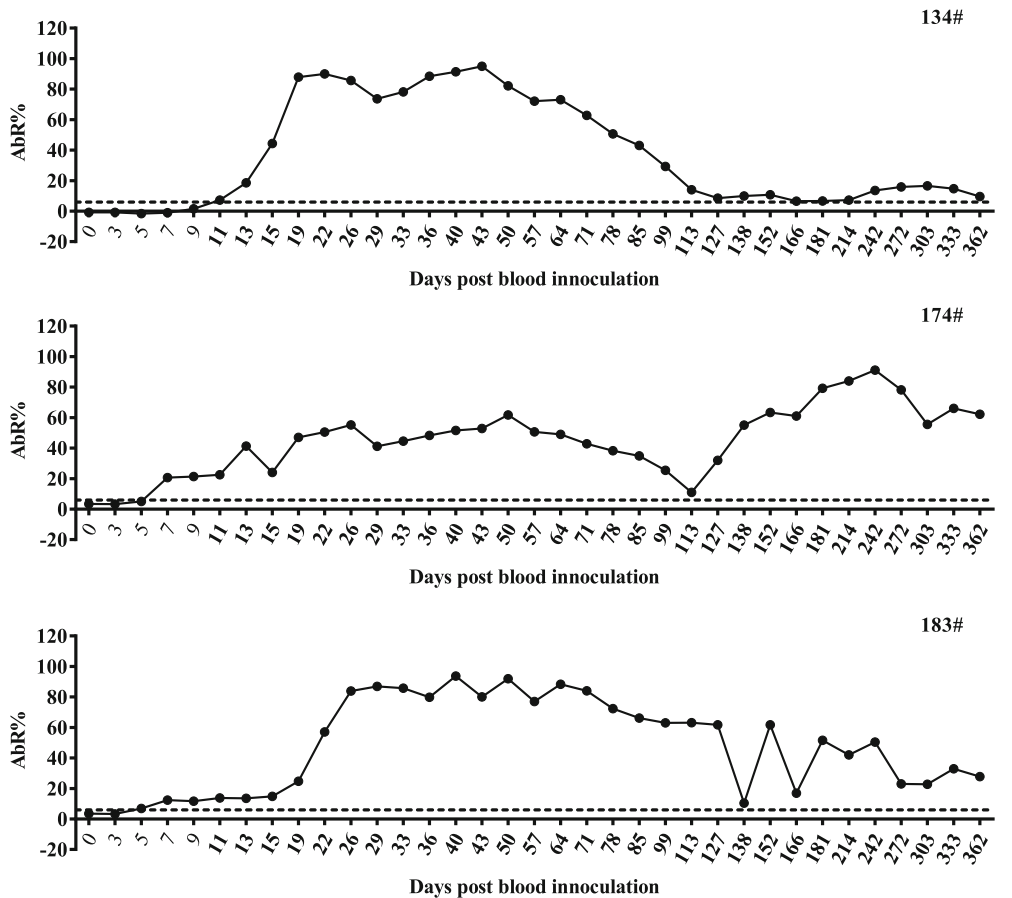

Fig. 9 Antibody kinetics for AAAP. Five sheep (Nos. 103, 106, 134, 174 and 183) infected with A. ovis were monitored for a year period, and the antibody response was tested by rAAAP ELISA

sheep were inoculated with infected blood from the Haibei strain the animals died. With the development and application of DNA-based tests such as conventional PCRs, specific qPCRs [16, 27], more and more studies have demonstrated high infection rates of $A$. ovis in North America, Europe, Africa, the Middle East and Asia, which have been well summarized by Renneker et al. [7]. These data indicate that more attention should be paid to the economic impact and health implications of $A$. ovis infection in small ruminants.

Two types of serological tests have been applied for analysis of $A$. ovis infection including complement fixation (CF) and a recombinant A. marginale Msp5 based competitive inhibition ELISA (CI-ELISA) [9, 10, 12, 28]. Although the A. marginale-derived CI-ELISA will successfully detect antibodies of $A$. ovis infection in sheep and goats, the fact that the Msp5 B-cell epitope is conserved among Anaplasma species [21, 29] means that the results need to be interpreted cautiously due to the potential for coinfections with other Anaplasma species in sheep and goats [30-33]. Further, the CI-ELISA cannot be used to quantitatively evaluate antibody titers, in the manner of a direct ELISA. A lack of knowledge of $A$. ovis-specific antigens has restricted the development of a species-specific test. Although a few A. ovis antigens, including Msp2, Msp3 and Msp4 have been reported [3, 34, 35], none of them have 
Table 1 Seroprevalence of A. ovis infection tested using rAAAP indirect ELISA in field samples from 23 provinces

\begin{tabular}{|c|c|c|c|c|}
\hline Province & Region & No. of sera & No. of positive sera & Positive rate (\%) \\
\hline \multirow[t]{3}{*}{$\overline{\text { Anhui }}$} & Chaohu & 34 & 18 & 52.94 \\
\hline & Hefei & 143 & 64 & 44.76 \\
\hline & Guangde & 15 & 5 & 33.33 \\
\hline Chongqing & Wanzhou & 23 & 3 & 13.04 \\
\hline \multirow[t]{7}{*}{ Gansu } & Lintan & 98 & 31 & 31.6 \\
\hline & Dingxi & 28 & 4 & 14.9 \\
\hline & Yongchang & 74 & 13 & 17.57 \\
\hline & Jiayuguan & 81 & 2 & 2.47 \\
\hline & Jiuquan & 18 & 1 & 5.56 \\
\hline & Jingtai & 69 & 9 & 13.04 \\
\hline & Sunan & 46 & 6 & 13.04 \\
\hline Guangdong & Zhaoqing & 37 & 19 & 51.35 \\
\hline \multirow[t]{4}{*}{ Guangxi } & Guilin & 79 & 34 & 43.04 \\
\hline & Jingxi & 35 & 11 & 31.43 \\
\hline & Tianyang & 25 & 8 & 32.00 \\
\hline & Pingxiang & 18 & 3 & 16.67 \\
\hline \multirow[t]{3}{*}{ Guizhou } & Guiyang & 95 & 6 & 6.32 \\
\hline & Qinglong & 29 & 22 & 75.86 \\
\hline & Rongjiang & 34 & 23 & 67.65 \\
\hline Hebei & Baoding & 151 & 17 & 11.26 \\
\hline Henan & Anyang & 85 & 8 & 9.41 \\
\hline Hubei & Suizhou & 68 & 9 & 13.24 \\
\hline \multirow[t]{2}{*}{ Hunan } & Xiangtan & 26 & 14 & 53.85 \\
\hline & Xinhuang & 29 & 8 & 27.59 \\
\hline \multirow[t]{4}{*}{ Inner Mongolia } & Chifeng & 134 & 42 & 31.34 \\
\hline & Manzhouli & 13 & 3 & 23.08 \\
\hline & Baotou & 11 & 0 & 0 \\
\hline & Bayan Nur & 11 & 4 & 36.36 \\
\hline \multirow[t]{3}{*}{ Jilin } & Changchun & 27 & 7 & 25.93 \\
\hline & Qianan & 14 & 2 & 14.29 \\
\hline & Yongji & 26 & 13 & 50.00 \\
\hline \multirow[t]{3}{*}{ Liaoning } & Anshan & 27 & 17 & 62.96 \\
\hline & Dandong & 28 & 5 & 17.86 \\
\hline & Huanren & 29 & 7 & 24.14 \\
\hline Ningxia & Wuzhong & 81 & 27 & 33.33 \\
\hline Qinghai & Qilianshan & 98 & 64 & 65.31 \\
\hline Shaanxi & yulin & 74 & 17 & 22.97 \\
\hline Shandong & Dongying & 90 & 38 & 42.22 \\
\hline \multirow[t]{2}{*}{ Shanxi } & Lvliang & 50 & 19 & 38.00 \\
\hline & Xinzhou & 195 & 98 & 50.26 \\
\hline \multirow[t]{2}{*}{ Sichuan } & Hejiang & 31 & 16 & 51.61 \\
\hline & Panzhihua & 31 & 13 & 41.94 \\
\hline Tibet & Lhasa & 113 & 46 & 40.71 \\
\hline Xinjiang & Akesu & 92 & 16 & 17.39 \\
\hline
\end{tabular}


Table 1 Seroprevalence of A. ovis infection tested using rAAAP indirect ELISA in field samples from 23 provinces (Continued)

\begin{tabular}{lllll}
\hline & Yili & 287 & 153 & 53.31 \\
& Habahe & 100 & 60 & 60.00 \\
\multirow{4}{*}{ Yunnan } & Kashi & 20 & 1 & 5.00 \\
& Honghe & 30 & 14 & 46.67 \\
& Fuyuan & 35 & 27 & 77.14 \\
Zhejiang & Yanshan & 34 & 25 & 73.53 \\
& Hangzhou & 52 & 33 & 63.46 \\
& Jinghua & 15 & 0 & 0 \\
Total & Lishui & 15 & 0 & 0 \\
\hline
\end{tabular}

been developed into an A. ovis-specific serological test. In the present study, we identified the aaap gene from the $A$. ovis genome from mass spectrometry data. Recombinant AAAP showed a specific reaction with $A$. ovis-positive sera in both Western blot and ELISA analysis, while no crossreactivity was observed with positive serum of $A$. bovis and other related agents. However, cross-reactivity with A. marginale-positive sera occurred in the rAAAP ELISA, most likely due to the presence of similar AAAP amino acid sequences in both $A$. ovis and $A$. marginale, such as multiple imperfect peptide repeats centred around the sequence ELKAIDA [36]. Rabbit anti-rAAAP serum was able to detect native AAAP on Western blots of purified A. ovis lysates from infected blood, which revealed multiple protein bands with a molecular size around $35 \mathrm{kDa}$. That is consistent with the fact that $A$. ovis contains tandemly duplicated copies of aaap in its genome [37]. Although a few studies have reported the infection of $A$. marginale in wild ruminant species such as bighorn sheep, white-tailed deer, etc. $[3,38]$, A. marginale infection of sheep and goats was not found in China and most of the world, which indicates that the AAAP indirect ELISA has the potential to be applied for establishing species-specific diagnostic assays for sheep and goats. However, only limited A. bovis serum samples and none of the serum samples of A. phagocytophilum, A. capra as well as Ehrlichia spp. were included in the present study, further evaluation of the specificity of the rAAAP ELISA method are needed.

In this study, an indirect ELISA was established using rAAAP for detection of antibodies to A. ovis infection. The accuracy of an ELISA test is dependent on the cutoff value used to classify samples as seropositive or not, and changing the cut-off value can change the results of the test $[38,39]$. The cut-off for the rAAAP-ELISA was determined to be $6.0 \%$ (AbR\%) when the minimal total number of diagnostic errors (false positives plus false negatives) was calculated after testing 434 negative and 163 positive reference sera. This is the most direct approach in defining the optimal cut-off for a serological test $[38,39]$. With this threshold, the sensitivity and specificity of the rAAAP ELISA were calculated to be 91.4 and $94.5 \%$, respectively.

The prospective use of the rAAAP ELISA in detecting $A$. ovis infection was verified by testing the antibody kinetics for 1 year in five experimentally infected sheep. The test could detect an antibody response 5 to 15 days postinfection, with this time frame being in agreement with the biological features of Anaplasma infection, which usually takes one to several weeks to establish infection $[9,40]$. After the infection was established, a sharply increasing antibody response appeared, and the high antibody titer lasted for around 3 months. A persistent antibody titer was detectable until the end of the experiment using the rAAAP ELISA. These results demonstrated the potential usefulness and applicability of this ELISA for detecting early infection and monitoring persistent $A$. ovis infection. In addition, a fluctuating antibody titer was seen during persistence in sheep Nos. 103, 106, 134 and 174, but was not so apparent in sheep No. 183. This is in line with two patterns of persistent bacteremia in $A$. ovis infected goats. The first pattern was characterised by cyclic fluctuation, similar to the pattern described for $A$. marginale infected cattle, while the bacteremia levels were relatively constant in the second pattern $[34,41,42]$. Whether these phenomena are related to the antigenic variation of the $m s p 2$ and $m s p 3$ multigene families resulting in cyclic rickettsemia during $A$. ovis persistent infection remains unknown [34], although this pattern has been demonstrated in A. marginale [41, 42].

With the established rAAAP ELISA, a large-scale study of 3138 sera from sheep and goats collected from 54 different locations in 23 provinces was undertaken. As a result, the seroprevalence of $A$. ovis infection was detected in almost all of the sampled regions, except Baotou in Inner Mongolia, and Jinghua and Lishi in Zhejiang Province. Negative results for these three regions are most likely due to the limited sample size because the presence of $A$. ovis infection has been demonstrated in Inner Mongolia and Zhejiang in our previous studies [9, 31]. A wide distribution 
of $A$. ovis infection in the investigated regions likely reflects the true situation in China, since the existence of $A$. ovis infection in most of these provinces has been reported recent years $[30,31,43,44]$.

\section{Conclusion}

An A. ovis derived antigenic protein, AAAP, was identified in the present study. The antigenicity of the recombinant AAAP was confirmed by testing $A$. ovis-positive sera and rabbit anti-rAAAP serum. Using rAAAP an indirect ELISA assay was established, and the assay has been proven to be an alternative serological diagnostic tool for investigating the prevalence of ovine anaplasmosis of sheep and goats. However, this method may be not specific for indicating exposure to A. ovis. Thus further studies are needed to characterise the aaap gene in other related pathogens and systematically evaluate the detection ability of the rAAAP ELISA for future application in the field.

\section{Abbreviations \\ AAAP: Anaplasma sp. appendage-associated protein; AbR\%: The specific antibody mean rate; AP: Alkaline phosphatase; BCIP: 5-bromo-4-chloro-3- indolyl phosphate; CAN: Acetonitrile; CF: Complement fixation; \\ CI-ELISA: Competitive inhibition enzyme-linked immunosorbent assay; DMSO: Dimethyl sulfoxide; EDTA: Ethylene diamine tetraacetie acid; ELISA: Indirect enzyme-linked immunosorbent assay; FA: Formic acid; FCA: Freund's complete adjuvant; IPTG: Isopropyl- $\beta$-d-thiogalactoside; LC-ESI-MSMS: Liquid chromatography-electrospray ionisation tandem mass spectrometry; Msp5: Major surface protein 5; NBT: Nitroblue tetrazolium; OD: Optical density; PBS: Phosphate-buffered saline; PCR LAMP: Loop- mediated isothermal amplification; PCR: Polymerase chain reaction; qPCR: Quantitative real-time PCR; SDS-PAGE: Sodium dodecyl sulfate- polyacrylamide gel electrophoresis; TBS: Tris-buffered saline}

\section{Acknowledgements}

Not applicable.

\section{Funding}

This study was financially supported by The National Key Research and Development Program of China (2017YFD0501200, 2016YFC1202000, 2016YFC1202002); the NSFC (31,502,091 and 31,502,054); ASTIP, FRIP (2014ZL010), CAAS; NBCIS CARS-38; 973 Program (2015CB150300); Jiangsu Co-innovation Center programme for Prevention and Control of Important Animal Infectious Diseases and Zoonoses, State Key Laboratory of Veterinary Etiological Biology Project.

\section{Availability of data and materials}

All data generated or analysed during this study are included in this published article.

\section{Authors' contributions}

$\mathrm{ZL}, \mathrm{J}$ and $\mathrm{HY}$ participated in the design of study and coordination. ZW and $J Y$ contributed to the identification of AAAP, recombinant expression of the AAAP and establishment and evaluation of AAAP ELISA. BK, ZL and GL contributed the data analysis. ZW, ZL, and BK drafted the manuscript. ZW, JY and QN conducted an animal experiment. All authors read and approved the final manuscript.

\section{Ethics approval}

The animal experiments were approved by Animal Ethics Committee of Lanzhou Veterinary Research Institute, Chinese Academy of Agricultural Sciences. All experiments were performed in strict accordance with the requirements of the Animal Ethics Procedures and Guidelines of the People's Republic of China.

\section{Consent for publication}

Not applicable.

\section{Competing interests}

The authors declare that they have no competing interest.

\section{Publisher's Note}

Springer Nature remains neutral with regard to jurisdictional claims in published maps and institutional affiliations.

\section{Author details}

${ }^{1}$ State Key Laboratory of Veterinary Etiological Biology, Key Laboratory of Veterinary Parasitology of Gansu Province, Lanzhou Veterinary Research Institute, Chinese Academy of Agricultural Sciences, Lanzhou, People's Republic of China. ${ }^{2}$ Department of Veterinary Microbiology and Pathology, Washington State University, Pullman, WA 99164, USA. ${ }^{3}$ Jiangsu Co-innovation Center for Prevention and Control of Important Animal Infectious Diseases, Yangzhou, China.

Received: 30 May 2017 Accepted: 17 July 2017

Published online: 28 July 2017

\section{References}

1. Krier JP, Ristic M. Anaplasmosis. VII. Experimental Anaplasma ovis infection in white-tailed deer (Dama virginiana). Am J Vet Res. 1963;24:567-72.

2. Kuttler KL. Infection of splenectomized calves with Anaplasma ovis. Am J Vet Res. 1981:42:2094-6.

3. de la Fuente J, Atkinson MW, Naranjo V, Fernandez de Mera IG, Mangold AJ, Keating KA, et al. Sequence analysis of the msp4 gene of Anaplasma ovis strains. Vet Microbiol. 2007;119:375-81.

4. Dumler JS, Barbet AF, Bekker CP, Dasch GA, Palmer GH, Ray SC, et al. Reorganization of genera in the families Rickettsiaceae and Anaplasmataceae in the order Rickettsiales: unification of some species of Ehrlichia with Anaplasma, Cowdria with Ehrlichia and Ehrlichia with Neorickettsia, descriptions of six new species combinations and designation of Ehrlichia equi and 'HGE agent' as subjective synonyms of Ehrlichia phagocytophila. Int J Syst Evol Microbiol. 2001;51:2145-65.

5. Friedhoff KT. Tick-borne diseases of sheep and goats caused by Babesia, Theileria or Anaplasma spp. Parassitologia. 1997;39:99-109.

6. de la Fuente J, Massung RF, Wong SJ, Chu FK, Lutz H, Meli M, et al. Sequence analysis of the msp4 gene of Anaplasma phagocytophilum strains. J Clin Microbiol. 2005:43:1309-17.

7. Renneker S, Abdo J, Salih DE, Karagenc T, Bilgic H, Torina A, et al. Can Anaplasma ovis in small ruminants be neglected any longer? Transbound Emerg Dis. 2013;60(Suppl 2):105-12.

8. Uilenberg G. General review of tick-borne diseases of sheep and goats world-wide. Parassitologia. 1997;39:161-5.

9. Lu W. Ovine anaplasmosis in northwest China. Trop Anim Health Pro. 1997; 29:16S-8S.

10. Hornok S, Elek V, de la Fuente J, Naranjo V, Farkas R, Majoros G, et al. First serological and molecular evidence on the endemicity of Anaplasma ovis and A. marginale in Hungary. Vet Microbiol. 2007;122:316-22.

11. Tibbitts T, Goff W, Foreyt W, Stiller D. Susceptibility of two Rocky Mountain bighorn sheep to experimental infection with Anaplasma ovis. J Wildl Dis. 1992:28:125-9.

12. Ndung'u LW, Aguirre C, Rurangirwa FR, McElwain TF, McGuire TC, Knowles DP, et al. Detection of Anaplasma ovis infection in goats by major surface protein 5 competitive inhibition enzyme-linked immunosorbent assay. J Clin Microbiol. 1995;33:675-9

13. Silaghi C, Santos AS, Gomes J, Christova I, Matei IA, Walder G, et al. Guidelines for the direct detection of Anaplasma spp. in diagnosis and epidemiological studies. Vector Borne Zoonotic Dis. 2017;17:12-22.

14. Ma M, Liu Z, Sun M, Yang J, Guan G, Li Y, et al. Development and evaluation of a loop-mediated isothermal amplification method for rapid detection of Anaplasma ovis. J Clin Microbiol. 2011;49:2143-6.

15. Torina A, Agnone A, Blanda V, Alongi A, D'Agostino R, Caracappa S, et al. Development and validation of two PCR tests for the detection of and differentiation between Anaplasma ovis and Anaplasma marginale. Ticks Tick Borne Dis. 2012;3:283-7.

16. Chi Q, Liu Z, Li Y, Yang J, Chen Z, Yue C, et al. Development of a real-time PCR assay for detection and quantification of Anaplasma ovis infection. Transbound Emerg Dis. 2013;60(Suppl 2):119-24. 
17. Shompole S, Waghela SD, Rurangirwa FR, McGuire TC. Cloned DNA probes identify Anaplasma ovis in goats and reveal a high prevalence of infection. J Clin Microbiol. 1989;27:2730-5.

18. McGuire TC, Davis WC, Brassfield AL, McElwain TF, Palmer GH. Identification of Anaplasma marginale long-term carrier cattle by detection of serum antibody to isolated MSP-3. J Clin Microbiol. 1991;29:788-93.

19. Palmer GH, McElwain T, Mcguire T, Kappmeyer L, Davis W, Stiller D. Recent advances in serological diagnosis of anaplasmosis: development of the Msp-5 competitive inhibition ELISA. Br. J. Psychiatry. 1994;171(5):420-6.

20. Visser ES, McGuire TC, Palmer GH, Davis WC, Shkap V, Pipano E, et al. The Anaplasma marginale msp5 gene encodes a 19-kilodalton protein conserved in all recognized Anaplasma species. Infect Immun. 1992;60:5139-44.

21. Dreher UM, de la Fuente J, Hofmann-Lehmann R, Meli ML, Pusterla N, Kocan $\mathrm{KM}$, et al. Serologic cross-reactivity between Anaplasma marginale and Anaplasma phagocytophilum. Clin Diagn Lab Immunol. 2005;12:1177-83.

22. Al-Adhami B, Scandrett WB, Lobanov VA, Gajadhar AA. Serological crossreactivity between Anaplasma marginale and an Ehrlichia species in naturally and experimentally infected cattle. J Vet Diagn Investig. 2011;23:1181-8.

23. Olmeda AS, Armstrong PM, Rosenthal BM, Valladares B, del Castillo A, de Armas F, et al. A subtropical case of human babesiosis. Acta Trop. 1997;67:229-34.

24. Yin H, Liu Z, Guan G, Liu A, Ma M, Ren Q et al. Detection and differentiation of Theileria luwenshuni and T. uilenbergi infection in small ruminants by PCR. Transbound Emerg Dis. 2008;55:233-7.

25. Perkins DN, Pappin DJ, Creasy DM, Cottrell JS. Probability-based protein identification by searching sequence databases using mass spectrometry data. Electrophoresis. 1999;20:3551-67.

26. Zweig MH, Campbell G. Receiver-operating characteristic (ROC) plots: a fundamental evaluation tool in clinical medicine. Clin Chem. 1993;39:561-77.

27. Torina A, Galindo RC, Vicente J, Di Marco V, Russo M, Aronica V, et al. Characterization of Anaplasma phagocytophilum and A. ovis infection in a naturally infected sheep flock with poor health condition. Trop Anim Health Prod. 2010;42:1327-31.

28. Zaugg $\mathrm{J}$. Experimental infections of Anaplasma ovis in pronghorn antelope. J Wildl Dis. 1987;23:205-10

29. Scoles GA, Goff WL, Lysyk TJ, Lewis GS, Knowles DP. Validation of an Anaplasma marginale cELISA for use in the diagnosis of $A$. ovis infections in domestic sheep and Anaplasma spp. in wild ungulates. Vet Microbiol. 2008;130:184-90.

30. Zhou Z, Nie K, Tang C, Wang Z, Zhou R, Hu S, et al. Phylogenetic analysis of the genus Anaplasma in southwestern China based on 16S rRNA sequence. Res Vet Sci. 2010;89:262-5.

31. Liu Z, Ma M, Wang Z, Wang J, Peng Y, Li Y, et al. Molecular survey and genetic identification of Anaplasma species in goats from central and southern China. Appl Environ Microbiol. 2012;78:464-70.

32. Ben Said M, Belkahia H, Karaoud M, Bousrih M, Yahiaoui M, Daaloul-Jedidi M, et al. First molecular survey of Anaplasma bovis in small ruminants from Tunisia. Vet Microbiol. 2015;179:322-6.

33. Ait Lbacha H, Alali S, Zouagui Z, El Mamoun L, Rhalem A, Petit E, et al. High prevalence of Anaplasma spp. in small ruminants in Morocco. Transbound Emerg Dis. 2017;64:250-63.

34. Palmer GH, Abbott JR, French DM, McElwain TF. Persistence of Anaplasma ovis infection and conservation of the msp-2 and msp-3 multigene families within the genus Anaplasma. Infect Immun. 1998;66:6035-9.

35. de la Fuente J, Lew A, Lutz H, Meli ML, Hofmann-Lehmann R, Shkap V, et al. Genetic diversity of Anaplasma species major surface proteins and implications for anaplasmosis serodiagnosis and vaccine development Anim Health Res Rev. 2005;6:75-89.

36. Stich RW, Olah GA, Brayton KA, Brown WC, Fechheimer M, Green-Church K, et al. Identification of a novel Anaplasma marginale appendage-associated protein that localizes with actin filaments during intraerythrocytic infection. Infect Immun. 2004;72:7257-64.

37. Dark MJ, Herndon DR, Kappmeyer LS, Gonzales MP, Nordeen E, Palmer GH et al. Conservation in the face of diversity: multistrain analysis of an intracellular bacterium. BMC Genomics. 2009;10:16.

38. Aubry P, Geale DW. A review of bovine anaplasmosis. Transbound Emerg Dis. 2011;58(1):1-30.

39. Yin H, Lu W, Luo J. Babesiosis in China. Trop Anim Health Prod. 1997;29:11S-5S.

40. Kocan KM, de la Fuente J, Blouin EF, Coetzee JF, Ewing SA. The natural history of Anaplasma marginale. Vet Parasitol. 2010;167:95-107.

41. Eid G, French DM, Lundgren AM, Barbet AF, McElwain TF, Palmer GH. Expression of major surface protein 2 antigenic variants during acute Anaplasma marginale rickettsemia. Infect Immun. 1996;64:836-41.
42. French DM, McElwain TF, McGuire TC, Palmer GH. Expression of Anaplasma marginale major surface protein 2 variants during persistent cyclic rickettsemia. Infect Immun. 1998;66:1200-7.

43. Qiu H, Kelly PJ, Zhang J, Luo Q, Yang Y, Mao Y, et al. Molecular detection of Anaplasma spp. and Ehrlichia spp. in ruminants from twelve provinces of China. Can J Infect Dis Med Microbiol. 2016;2016:9183861.

44. Zhang Y, LV Y, Zhang F, Zhang W, Wang J, Cui Y, et al. Molecular and phylogenetic analysis of Anaplasma spp. in sheep and goats from six provinces of China. J Vet Sci. 2016:17:523-9.

\section{Submit your next manuscript to BioMed Central and we will help you at every step:}

- We accept pre-submission inquiries

- Our selector tool helps you to find the most relevant journal

- We provide round the clock customer support

- Convenient online submission

- Thorough peer review

- Inclusion in PubMed and all major indexing services

- Maximum visibility for your research

Submit your manuscript at www.biomedcentral.com/submit
) Biomed Central 